\title{
Seismicity patterns during a period of inflation at Sierra Negra volcano, Galápagos Ocean Island Chain
}

\author{
Lindsey Davidge ${ }^{1}$, Cynthia Ebinger ${ }^{1 *}$, Mario Ruiz ${ }^{2}$, Gabrielle Tepp ${ }^{3}$, Falk Amelung4, Dennis \\ Geist 5 , Dustin Coté ${ }^{1}$ Juan Anzieta ${ }^{2}$
}




\section{ABSTRACT}

17 Basaltic shield volcanoes of the western Galápagos islands are among the most rapidly

18 deforming volcanoes worldwide, but little was known of the internal structure and brittle

19 deformation processes accompanying inflation and deflation cycles. A 15-station broadband

20 seismic array was deployed on and surrounding Sierra Negra volcano, Galápagos from July

212009 through June 2011 to characterize seismic strain patterns during an inter-eruption

22 inflation period and to evaluate single and layered magma chamber models for ocean island

23 volcanoes. We compare precise earthquake locations determined from a $3 \mathrm{D}$ velocity model and

24 from a double difference cluster method. Using first-motion of P-arrivals, we determine focal

25 mechanisms for 8 of the largest earthquakes $\left(M_{L} \leq 1.5\right)$ located within the array. Most of the

262382 earthquakes detected by the array occurred beneath the broad ( 9 km-wide) Sierra Negra

27 caldera, at depths from surface to about $8 \mathrm{~km}$ below sea level. Although outside our array,

28 frequent and larger magnitude $\left(\mathrm{M}_{\mathrm{L}} \leq 3.4\right)$ earthquakes occurred at Alcedo and Fernandina

29 volcano, and in a spatial cluster beneath the shallow marine platform between Fernandina and

30 Sierra Negra volcanoes. The time-space relations and focal mechanism solutions from a 4-day

31 long period of intense seismicity June 4-9, 2010 along the southeastern flank of Sierra Negra

32 suggests that the upward-migrating earthquake swarm occurred during a small volume

33 intrusion at depths $5-8 \mathrm{~km}$ subsurface, but there was no detectable signal in InSAR data to

34 further constrain geometry and volume. Focal mechanisms of earthquakes beneath the steep

35 intra-caldera faults and along the ring fault system are reverse and strike-slip. These new

36 seismicity data integrated with tomographic, geodetic, and petrological models indicate a

37 stratified magmatic plumbing system: a shallow sill beneath the large caldera that is supplied by

38 magma from a large volume deeper feeding system. The large amplitude inter-eruption

39 inflation of the shallow sill beneath the Sierra Negra caldera is accompanied by only very small

40 magnitude earthquakes, although historical records indicate that larger magnitude earthquakes 
$41(\mathrm{Mw}<6)$ occur during eruptions, trapdoor faulting episodes without eruptions, and large

42 volume flank intrusions.

\section{Introduction}

Movement of oceanic plates over anomalously hot, upwelling mantle produces chains of volcanoes, as in Hawaii or the Galápagos. The upwelling mantle produces basaltic magmas,

47 which are stored in crustal chambers, retained as cumulates, and intruded as dikes and sills,

48 thickening the crust [e.g., Coffin and Eldholm, 1994; Lyons et al, 2007]. The state of stress within the volcanoes is mostly controlled by magma replenishment and discharge from crustal reservoirs, gas exsolution, caldera formation, and edifice construction [e.g., Pinel and Jaupart,

51 2003; Gregg et al., 2012; Corbi et al., 2015]. The spatial distribution and focal mechanisms of earthquakes provide constraints on state of stress in space and time, and geodetic methods detect pressure changes caused by gas exsolution or magma chamber discharge or

54 replenishment [e.g., Amelung et al., 2000; Bagnardi and Amelung, 2012].

The 7 active volcanoes in the western Galápagos have pronounced surface deformation

56 patterns, providing an opportunity to probe ocean island formation (Fig. 1). Each volcano has a

57 wide $(\sim 9 \mathrm{~km})$, deep (ca. $1 \mathrm{~km}$ ) summit caldera. The flanks also deform: over $6 \mathrm{~m}$ of rapid uplift

58 occurred along the western flank of Darwin volcano in 1954, exposing several square kilometers

59 of the seafloor of Urvina Bay and stranding corals, sharks, and other marine life [Colgan, 1987].

60 A similar event occurred on Fernandina's northeast side in 1927 [e.g. Poland, 2014]. More than

$615 \mathrm{~m}$ of subsidence occurred within a period of hours during the 2005 Sierra Negra eruption,

62 during which $150 \times 10^{6} \mathrm{~m}^{3}$ of basalt was erupted [Geist et al., 2008]. The surface deformation is

63 attributed to magma intrusion, circumferential and unusual intra-caldera faulting, as well as

64 dike intrusion [e.g., Amelung et al., 2000; Geist et al., 2006; 2008; Chadwick et al., 2006, 2011;

65 Bagnardi and Amelung, 2012; Poland, 2014]. 
Despite these strong geodetic signals and potential for moderate magnitude earthquakes,

67 little was known of the spatial or temporal distribution of seismicity associated with the rapid

68 vertical deformation cycles on the Galápagos island volcanoes. The Sierra Negra Integrated

69 Geophysical NETwork (SIGNET) array was deployed around Sierra Negra and Cerro Azul

70 volcanoes, which form southern Isabela Island, between July 2009 and June 2011 (Fig. 2).

71 Sierra Negra and Cerro Azul are two of the most active volcanoes in the Galápagos, with recent

72 eruptions in 2005 and 2008, respectively. Using the SIGNET array and the permanent Global

73 Seismic Network station PAYG on nearby Santa Cruz Island, we locate 2382 local earthquakes

74 recorded on 3 or more temporary broadband seismic stations using absolute and double-

75 difference algorithms. Our aim is to map the distribution of brittle strain within Sierra Negra

76 volcano and the surrounding ocean island platform, and to provide new constraints on the

77 geometry of magma reservoirs and conduits to the surface. Our analyses enable us to evaluate

78 the kinematics of faulting within the caldera, along the ring fault system, and the flanks of the

79 rapidly deforming volcano. We compare earthquake locations from an absolute location

80 algorithm, body wave tomography [Tepp et al., 2014], and double-difference methods, and we

81 determine focal mechanisms of the largest earthquakes located within the network. Our results

82 are used to inform the volcanic hazards monitoring program for the Galápagos Islands.

\section{2. Background}

Located on the eastward-moving Nazca plate ca. $1000 \mathrm{~km}$ west of continental Ecuador,

85 the westward-younging Galápagos archipelago is marked by a chain of active and extinct

86 volcanoes formed from repeated eruptions and intrusions of basaltic magma above the

87 Galápagos hotspot (Fig. 1). Plume interactions with the nearby Galápagos spreading ridge to the

88 north complicate the simple east-to-west younging pattern, locally imposing a NE-SW directed

89 minimum stress direction, and explaining the NW-oriented volcanic ridges in the northern

90 (near-ridge) sector of the archipelago [Mittelstaedt and Ito, 2005; Harpp and Geist, 2002]. The 
$\mathrm{J}$-shaped Isabela Island comprises 6 active shield volcanoes, while Fernandina Island is a single

92 shield volcano (Figs. 1, 2).

Receiver function and tomography studies reveal a thinned mantle transition zone beneath the western Galápagos Archipelago [Hooft et al., 2003], consistent with a mantle plume upwelling beneath Fernandina volcano [e.g., Ito \& Lin, 1995; Villagomez et al., 2014]. Rayleigh wave tomography and receiver function studies of the Galápagos Archipelago reveal anomalously low-velocity upper mantle between $75-150 \mathrm{~km}$, overlain by a variable-thickness high-velocity lid [Villagomez et al., 2007; Rychert et al., 2014]. The lid is 30 km thicker beneath Isabela and Fernandina Islands than beneath the eastern part of archipelago [Villagomez et al., 2007; Rychert et al., 2014]. Fernandina, in particular, erupts basalts with anomalously high ${ }^{3} \mathrm{He} / 4 \mathrm{He}$, which has been interpreted as contributions from a deep mantle source [e.g., Graham et al., 1993; Kurz \& Geist, 1999]. SKS-splitting patterns show small amounts of anisotropy in directions sub-parallel to fissures on Isabela Island, suggesting that flow is either sub-vertical, or that anisotropy accrued from different depths has different azimuths [Fontaine et al., 2005].

Crustal thickness beneath the Galápagos is loosely constrained by a WSW-striking seismic refraction profile south of Isabela Island [Toomey et al., 2001], ambient noise tomography from a widely-spaced array [Villagomez et al., 2011], body-wave tomography from the SIGNET array [Tepp et al., 2014], gravity studies [Feighner \& Richards, 1994], and receiver function studies [Rychert et al., 2014]. Crustal thickness increases sharply from $\sim 8 \mathrm{~km}$ west of the platform, to more than $15 \mathrm{~km}$ on the platform [Villagomez et al., 2011; Rychert et al., 2014; Tepp et al., 2014]. Crustal velocities are $~ 10 \%$ lower in the volcanically active western sector of the archipelago, as compared to its older, largely inactive eastern portion [Villagomez et al., 2010]. Body-wave tomography from the SIGNET array reveals a broad low-velocity region (>25 km-wide) below Sierra Negra at depths $\sim 8-15 \mathrm{~km}$ interpreted as a volumetrically large crystal- 
mush zone [Tepp et al., 2014]. Tomography, receiver function, and petrological results are consistent with crustal growth by accretion of mafic cumulates and eruption of evolved basalts [Reynolds et al, 1995a; Tepp et al., 2014].

The shallow crustal structure of Sierra Negra largely is constrained by models of surface deformation. Models of surface deformation during and after the 2007 eruption are best fit with

121 a flat-topped inflating body with top at $\sim 2 \mathrm{~km}$ subsurface, assumed to be a melt-rich sill [Yun et

122 al., 2006; 2007]. The geometry of the bottom of the sill(s) is poorly constrained by surface 123 deformation patterns [Yun et al., 2007]. The 3D attenuation model of Rodd et al. [2016] reveals 124 patchy, highly attenuating zones between $0.5 \mathrm{~km}-3 \mathrm{~km}$ below sea level, interpreted as shallow 125 magma bodies. The zone between the shallow sill and the deeper crystal mush zone remained 126 poorly determined.

Most of the active volcanoes forming Isabela and Fernandina islands have wide, deep 128 summit calderas (Fig. 2). Of Isabela's volcanoes, the $60 \mathrm{~km}$-long Sierra Negra volcano is the 129 most voluminous and has the largest summit caldera with an area of $82 \mathrm{~km}^{2}$ [Reynolds et al, 130 1995b]. The caldera is surrounded by steep ring faults that may have accommodated magma 131 chamber pressure changes in the past. Unusually, the ca. $9 \mathrm{~km}$-wide caldera floor hosts a fault132 bounded curvilinear ridge that has slipped during eruptions and during the inter-eruption cycle 133 [e.g., Amelung et al., 2000; Jonsson et al., 2005; Chadwick et al., 2006; Yun et al., 2007](Figs. 1, 134 2). Models of surface deformation and dip-slip displacements measured along fault surfaces 135 indicate that the southern sector of the ridge accommodates inflation of a shallow melt-rich sill 136 in a trapdoor fashion [Amelung et al., 2000; Jonsson et al., 2005; Geist et al., 2008]. Two 137 trapdoor events occurred in 2005, with the second accompanied by a major eruption along the 138 northern caldera margin, which functioned as a leaky hinge zone [Chadwick et al., 2006; Geist et 139 al., 2008; 2014]. A magnitude 4.5 earthquake occurred during the first event [April, 2005; 140 Chadwick et al., 2006], and mb 4.6 and Mw 5.5 events occurred prior to and during the eruption 
141 and trapdoor event [October, 2005; Geist et al., 2008]. The source mechanism of the largest 142 earthquake that occurred 3 hours before the effusive eruption had a vertical T-axis, and may 143 have been associated with the faulting episode [Shuler et al., 2013].

144 Although seismometers have been deployed temporarily on some of the Galápagos 145 islands, station spacing generally has been too wide, or data recovery too poor, to locate all but 146 the largest events (Fig. 1). The NEIC catalogue of teleseismic and some local earthquakes shows 147 moderate levels of seismicity within and around the Galápagos archipelago $(\mathrm{M}<6)$ and $91^{\circ} \mathrm{W}$ 148 transform fault. The proximity of volcanoes and the $\sim 30 \mathrm{~km}$ location accuracy of the global 149 seismic network, however, makes it difficult to correlate teleseisms with specific volcanoes, or to 150 detect activity prior to or during eruptions [e.g., Filson et al., 1973; Fox et al., 2001] (Fig. 1). 151 Global Centroid Moment Tensor (GCMT) solutions show a wide range of fault slip behaviors, 152 including strike-slip mechanisms and E-W to NW-SE compression with a significant component 153 of non double-couple deformation [Ekstrom et al., 2012].

154 Based on the orientation of aligned chains of eruptive centers on southern Isabela Island, 155 Reynolds et al. [1995b] suggest that the regional stress field is rotated from NE-SW to ENE156 WSW, although the stress interactions between nearby volcanoes may be equally or more 157 important [e.g., McGovern, 2007; Bagnardi and Amelung, 2012] (Fig. 2). The wide, deep 158 caldera reduces the overburden above the magma chamber, promoting circumferential diking 159 around the caldera [e.g., Chestler and Grosfils, 2013; Corbi et al., 2015]. The orientations and 160 focal mechanisms provide constraints on the interplay between these tectonic and body forces. 161 The time-space distribution of earthquakes, as well as the surface deformation patterns, provide 162 information on stress localization and kinematics needed to evaluate models of inter-eruption 163 state-of-stress.

\section{3. Data}


A temporary, sparse IGEPN network (1999-2001) and our SIGNET seismic array (20092011) provide, for the first time, a baseline for monitoring Sierra Negra volcano, as well as activity levels at Cerro Azul, Alcedo, and Fernandina volcanoes and the shallow platforms immediately outside our array. The SIGNET broadband seismic array was deployed around the coastline of southern Isabela Island through a collaboration between Instituto Geofísico

170 Nacional Escuela Politecnica, University of Rochester, University of Miami, the University of 171 Idaho, and the Charles Darwin Foundation (Fig. 2). Ten IRIS-PASSCAL Guralp 3T, two Guralp 172 40T, and 1 University of Rochester Trillium 120 and 2 Trillium-Compact seismometers recorded 173 local and teleseismic activity between August 3, 2009 and June 17, 2011. Data was recorded at 174100 samples per second at GSo8, GS14 and GS15, and 40 sps on the IRIS-PASSCAL stations.

\section{4. Methods}

$176 \quad 4.1$ Locations

P- and S- wave arrivals were hand-picked on Butterworth filtered vertical and transverse 178 components, respectively, to produce a data base of 2382 events, with 13,188 P-wave phases and 1797885 S-wave phases. Uncertainties in P-wave picks were estimated in $0.05 \mathrm{~s}$ intervals (e.g., $180 \quad 0.05 \mathrm{~s}, 0.1 \mathrm{~s}$ ); uncertainties in S-wave picks were estimated in $0.1 \mathrm{~s}$ intervals. All events were 181 initially located using the absolute location program Hypoinverse200o [Klein 2002]. The 182 program VELEST [Kissling et al., 1994] was used to invert simultaneously for one-dimensional 183 Vp and Vs assuming the initial starting velocity model of Toomey et al. [2001]. This velocity 184 model was developed using events with at least six recorded arrival times with $<180^{\circ}$ azimuthal 185 gap, and was used with both the absolute and relative double-difference location methods, and 186 as a starting model for the tomography. We estimate a $\mathrm{Vp} / \mathrm{Vs}$ ratio for the crust of 1.8 using a 187 Wadati diagram of all well-located arrivals from earthquakes within the array (Fig. SM1, 188 Supplementary Material). 
The double differencing relative earthquake algorithm HypoDD is used to relocate 190 clusters of earthquakes [Waldhauser and Ellsworth, 2000]. We use V2.1beta that allows for 191 variations in the elevations of stations, enabling relocation of some earthquakes within the 192 edifice. In this method, the observed minus predicted phase travel time differences between 193 pairs of closely located earthquakes detected at common stations are related to the differences in 194 the vector connecting their hypocenters. By effectively reducing seismic path length, location 195 errors related to $3 \mathrm{D}$ velocity variations are minimized. The double-difference equations are used 196 to linearize the earthquake location problem, effectively removing common mode errors, and 197 reducing the effects of local velocity variations [Waldhauser and Ellsworth, 2000]. While the 198 double-difference method provides relative locations, iterative relative location solutions 199 converge toward the absolute location [Waldhauser \& Ellsworth, 2000]. We use cross200 correlation of waveforms to identify repeating earthquakes and to reduce location errors 201 associated with arrival time picks in areas of clustered seismicity. Reported errors are estimated 202 with singular-value decomposition.

\subsection{Magnitudes}

Local magnitudes $\left(\mathrm{M}_{\mathrm{L}}\right)$ for each earthquake were estimated by first measuring maximum 206 zero-to-peak amplitude on simulated N-S and E-W horizontal component Wood-Anderson 207 displacement seismograms, after removal of instrument response. These measurements are 208 used in conjunction with the computed hypocentral distance between the station and 209 earthquake to estimate local magnitude $\left(\mathrm{M}_{\mathrm{L}}\right)$. We compute the magnitude at each horizontal 210 component of each station discretely, and then use the average of these values as the overall 211 earthquake magnitude. Earthquake magnitudes are estimated using a local magnitude scale and 212 distance correction terms for incipient seafloor spreading zones where local attenuation is high 213 [Keir et al., 2006], in the absence of a local magnitude scaling relation. This scaling is consistent 
214 with the high P-wave attenuation at depths of $0.5-8.5 \mathrm{~km}$ below sea level estimated by the 215 attenuation tomography model of Rodd et al. [2016]. A site-specific magnitude scale awaits a 216 time series that spans an eruption cycle.

$218 \quad 4.3$ Focal Mechanisms

219 The small magnitude of earthquakes recorded during the SIGNET deployment precludes 220 waveform modeling, and we assume a double-couple solution. This may be an over221 simplification based on earlier studies of teleseismic events associated with eruptive activity 222 [e.g., Shuler et al., 2013]. We use the first-motion modeling program FOCMEC, which finds the 223 best-fitting strike, dip, and rake of $1 \leq \mathrm{M}_{\mathrm{L}} \leq 4.6$ earthquakes with standard errors [Snoke et al., 224 2003].

\section{5. Results}

$227 \quad 5.1$ Local Magnitude and b-value

228 Magnitudes of earthquake locations within the array are all less than $\mathrm{M}_{\mathrm{L}}=2.6$ (Fig. 3,

229 SM2). The $b$-value for the SIGNET database is estimated using the maximum-likelihood

230 approach [Aki, 1965] (Fig. SM2). Based on the low-magnitude fall-off in the magnitude-

231 frequency relation, the magnitude of completeness is $M_{L}=1.1$. The linear segment of the curve

232 between $1.1<\mathrm{M}_{\mathrm{L}}<1.6$ is fit with a b-value of 3.1, a very high value characteristic of earthquakes 233 around shallow magma chambers [e.g., Brandsdottir and Einarsson, 1979; Murru et al., 1999].

Earthquakes recorded on 4 or more stations and with 6 or more P- and S-arrival time

237 measurements are used for locations. Almost all of the 2382 earthquakes were volcano-

238 tectonic events with impulsive P-arrivals, commonly indistinct S-arrivals, unusually long codas, 
and peak frequencies $<10 \mathrm{~Hz}$. No unusually low-frequency earthquakes were detected,

240 although tremor was frequently detected at GS15 near the center of the 9-km-wide caldera.

241 Wave noise at coastal stations complicates more rigorous analyses of spectral content. All

242 depths we report are referenced to sea-level, rather than elevation. The mean depth of

243 earthquakes within or near the array is $6.5 \mathrm{~km}$, which places them within the upper oceanic

244 crust and volcanic edifice where velocities are laterally variable [Tepp et al., 2014]. The mean

245 horizontal and vertical uncertainties are 1.98 and $2.19 \mathrm{~km}$, respectively.

246 Earthquakes occurred throughout the Isabela Island region, with persistent spatial

247 clusters around Sierra Negra and Alcedo calderas and on the shallow marine shelf between

248 Fernandina and Sierra Negra volcanoes (Figs. 1, 3). Seismicity is largely restricted to the

249 uppermost $2 \mathrm{~km}$ of Sierra Negra; depths of earthquakes on Alcedo volcano and the shallow

250 platform outside the array are not well constrained (Fig. 3). Cerro Azul volcano, which last

251 erupted in May 2008, was largely inactive seismically during the 2009-11 period [Global

252 Volcanism Program, 2008]. The largest earthquakes occurred on Fernandina $\left(\mathrm{M}_{\mathrm{L}} \leq 2.5\right)$ and

253 Alcedo $\left(M_{L} \leq 3 \cdot 3\right)$, whereas the largest earthquakes on Sierra Negra were $M_{L} \leq 1.5$ (Fig. 3). An

254 intense and persistent cluster of earthquakes occurred on the submarine southeastern flank of

255 Fernandina volcano (Fig. 3). The subaerial southeastern flank of Fernandina was uplifted in

256 2007, and InSAR patterns were modeled as a sill intrusion sourced from a ca. $5 \mathrm{~km}$ bsl magma

257 chamber [Bagnardi and Amelung, 2012]. New seafloor imaging data reveal a zone of young

258 submarine eruptive centers about $3 \mathrm{~km} \mathrm{NW}$ of the earthquake cluster [Soule et al., 2016]. Given

259 location errors of these events outside our array, they could be coincident with the young cones.

260 Sierra Negra seismicity is localized to the caldera region (Fig. 3). There is no clear

261 correlation of seismicity and the circumferential and radial eruptive vents, except along the E-W

262 striking chain east of the caldera (Figs. 3, 4). Several hundred $M_{L} \leq 1.4$ earthquakes occurred on

263 the southern flank of Sierra Negra between 4 and 10 June 2010; this swarm is analyzed in more 
264 detail below (Fig. 3). Two other hours-long migrating swarms initiated beneath the northern 265 side of the caldera on March 25, 2014 and March 5, 2011 (Fig. 4). The histogram of time 266 variations in seismicity shows no increase in seismicity during the El Niño in early 2011 when 267 heavy rainfall occurred in normally arid areas.

268 Earthquakes near the edge of the network and shallow earthquakes with only 6 phase 269 readings have the largest errors. Owing to the shallow depths and clustered nature of the 270 earthquakes, we use the double-difference algorithm to refine locations for earthquakes along 271 the caldera ring fault system during the June 2010 swarm locations.

\section{$5 \cdot 3$ Fault Kinematics}

274 Earthquakes with clear P-arrivals on 7 or more stations and with good azimuthal 275 distribution were screened for focal mechanisms. Of the 18 earthquakes considered, 6 had 276 azimuthal gaps $<120^{\circ}$ and strike, dip and rake of the slip plane constrained to $\pm 10^{\circ}$, with no 277 phase errors (Table 1, Fig. 5, Fig. SM3). Two additional events had strike, dip and rake of the 278 slip plane constrained to $\pm 25^{\circ}$. The resulting focal mechanisms show a wide range of solutions: 279 reverse or oblique-reverse (4), strike-slip (2), and normal (2). The 4 focal mechanisms of 280 earthquakes beneath the sinuous ridge have steep $\left(51^{\circ}-80^{\circ}\right)$ nodal planes. The reverse fault 281 planes indicate a compressional state within the uppermost $3 \mathrm{~km}$ bsl beneath the caldera during 282 the inter-seismic cycle (Table 1). Given the complexity of the sinuous ridge structure, we cannot 283 distinguish between inward and outward-dipping reverse faults from the distribution and 284 mechanisms of earthquakes alone. These focal mechanisms, however, provide information on 285 deformation along the hinge zone for the $\sim \mathrm{E}-\mathrm{W}$ trending trapdoor fault. The February 13, 2010 286 strike-slip mechanisms occurred beneath the ring fault system, whereas the August 17, 2010 287 earthquake may have occurred along faults of the sinuous ridge or the nearby ring fault system. 
The two reverse mechanisms on the southeastern flank occurred during the June 2010 swarm, 289 and the mechanisms are nearly identical.

\subsection{Double Difference Analyses}

292 We use the GISMO suite of Reyes and West [2011] to calculate the lag matrix needed to 293 match both P- and S-wave arrival times. Correlation coefficients were determined for all 294 selected waveforms and used to assign uncertainty values to the lag matrix, which contains the 295 shift factor given to each adjusted waveform. The time window was varied to ensure that surface 296 waves were excluded from the time window. Additionally, ocean wave microseismicity proved 297 one of the biggest challenges to analyses, leading to variable station coverage in the correlated 298 pairs. The maximum separation between hypocenters of linked events was set at $8 \mathrm{~km}$ to 299 maximize the number of highly correlated pairs. The average offset between linked events was $300 \quad 2.21 \mathrm{~km}$, with a maximum offset of $7.96 \mathrm{~km}$. Cross-correlation shift factors were applied for all 301 linked events with a correlation coefficient higher than o.6 (1289 events); 554 of those linked 302 events were observed by correlated waveforms from 5 or more stations. We input 77935 total P303 phase pairs and 49240 S-phase pairs, with the remaining 4845 phase pairs considered as 304 outliers, based upon the conditions defined above.

305 We used both cross-correlation and catalogue differential travel times with equal 306 weightings to iteratively solve for the caldera and flank cluster event locations. After testing, we 307 chose a damping factor of 60 for the first 10 iterations, and a damping factor of 50 for the last 308 ten iterations. For the caldera swarm, 73381 differential times were used with 406 caldera 309 earthquakes to relocate a cluster of 171 events. The average offset between linked events was 2.21 $310 \mathrm{~km}$. Inclusion of station elevations enables detection of some shallow earthquakes, but almost $31170 \%$ of the $\mathrm{P}$ and S arrivals were rejected as 'airquakes', owing to complexity of ray tracing from 
312 stations at or near sealevel into the volcanic edifice with its heterogeneous shallow velocity

313 structure [e.g., Tepp et al., 2014; Rodd et al., 2016].

314 The relocated earthquakes shown in map view in Figure 6 are more focused than the

315 absolute location results (Fig. 3). Horizontal uncertainties are 0.02 to $5.77 \mathrm{~km}$ with a mean of

$3161.01 \mathrm{~km}$, and depth errors are 0.29 to $6.32 \mathrm{~km}$ with a mean of $1.21 \mathrm{~km}$ for the caldera and a mean

317 of 0.98 for the June 2010 dike swarms. In comparison to the absolute error uncertainties, the

318 improved $\mathrm{P}$ and S-wave onset times and double-differencing reduces uncertainties by a factor of

319 ca. 2, in part because almost 70\% of the shallowest events were rejected.

\section{5 Comparison with $3 D$ Velocity Model Locations}

Absolute and relative location methods of shallow earthquakes rely on 1D velocity models that may be poor representations of laterally heterogeneous velocity structure within the

324 shallow edifice of a volcanic complex. Shallow events located using the $3 \mathrm{D}$ tomographic model 325 of Sierra Negra provide additional details on structure, and they provide a means to evaluate 326 bias and errors associated with the $1 \mathrm{D}$ velocity model used in absolute and double-difference 327 calculations (Fig. 7). Depth histograms provide one means to evaluate systematic variations in 328 depths between the absolute locations and the $3 \mathrm{D}$ velocity model results (Fig. 8). The 329 tomographic model uses a subset of earthquakes that are well distributed and have 7 or more 330 phase picks, but it is a smaller subset of the database. The $3 \mathrm{D}$ velocity model places a significant 331 percentage of earthquakes within the upper $2 \mathrm{~km}$ of the crust, including many that were 332 excluded as 'air-quakes' in the double-difference algorithm. The comparison of absolute 333 locations and the 3D relocation reveals no systematic shift in the depth distribution, except in 334 the depth ranges -1 to $1 \mathrm{~km}$ below sea-level (bsl)(Fig. 8). The shallower depths for earthquakes 335 relocated using the 3D models are not surprising, given the heterogeneity of the uppermost $2 \mathrm{~km}$ 336 and the complex seismic ray paths through the volcanic edifice. 


\section{Discussion}

As outlined below, Figure 9 places the seismicity in the context of our current knowledge

340 of the subsurface structure of Sierra Negra as derived from seismic imaging [Rychert et al.,

3412014 ; Tepp et al., 2014; Rodd et al., 2016] and from models of geodetic data [Jonsson et al.,

342 2005; Yun et al., 2007]. Below we discuss specific subsets of the earthquake data set and place

343 them in a context of volcano deformation and ocean island evolution.

$344 \quad 6.1$ Inflation and Seismicity

345 InSAR data for the time period of the array reveal $0.6 \mathrm{~m}$ of inflation in line-of-sight, with

346 little or no deformation on the flanks [Baker, 2012](Fig. SM4). Continuous GPS data from

347 station GVo2 in the center of Sierra Negra caldera shows $0.78 \mathrm{~m}$ of uplift from August 2009

348 through June 2011 relative to GVo1 on the NW flank (Fig. SM5). The footprint of the

349 deformation is small, and almost entirely restricted to the caldera (Fig. SM4). The inflation was

350 symmetrical and in the same pattern as observed since 1992. There was no inflection in the

351 deformation about the flank intrusion or any other of the identified seismic events. These

352 patterns indicate steady inflation with a pattern similar to previous inflation periods [Amelung

353 et al., 2000].

354 The southeastern flank of Fernandina volcano showed broad uplift in 2006 and 2007

355 [Bagnardi and Amelung, 2012], and it was seismically active during the time period of our array.

356 Whether the cone field imaged by Soule et al. [2016] is sourced from Fernandina or a discrete

357 pressurized magma body elsewhere awaits future marine seismic studies.

358 Although earthquakes on Alcedo are outside our array and have largely indeterminate

359 depths, we can correlate periods of seismic activity with deformation revealed in InSAR data.

360 The number of events increases from ca. 15 per month to 34 per month over the period

361 December 2009 to March 2010 when the Alcedo caldera floor dropped by about $12 \mathrm{~cm}$, after a 
ca. 2-year period of inflation [25 cm; Baker, 2012](Figure SM6). There are no InSAR data from

363 the region after 2010, so we cannot correlate a second pulse of seismicity in March-April 2011

364 with ground deformation patterns.

\section{2 Vertical stratification of the Sierra Negra magmatic system}

The presence of persistent and intense seismicity at depths between $2 \mathrm{~km}$ and the top of the crystal mush zone imaged in crustal tomography at ca. $8 \mathrm{~km}$ below sea-level indicates that there are two or more magma bodies beneath Sierra Negra (Fig. 9). Excluding the zone of highly clustered earthquakes along the eastern side of the caldera (Fig. 6), there is a subtle gap in seismicity between 1 and $2 \mathrm{~km}$ bsl (Fig. 9). Profiles at a range of azimuths show these same

373 (Fig. SM7).

374 Our results, placed within the context of tomographic and geodetic models, suggests that the 375 magmatic complex beneath Sierra Negra is layered. Models of geodetic data place strong 376 constraints on the top of a melt rich sill at $1 \mathrm{~km}$ below sea level and with spatial limits roughly 377 coinciding with the $\sim 9 \mathrm{~km}$-wide caldera, but the bottom was poorly constrained [Yun et al., 378 2007]. Rodd et al. [2016] image a highly attenuating body at depths between 0.5 and $3 \mathrm{~km}$ 379 below sea-level, which loosely coincides with the shadow zone in seismicity. We interpret these 380 patterns as evidence for a shallow melt-rich sill with top $1 \mathrm{~km}$ bsl, and a base at about $2 \mathrm{~km}$ bsl 381 (Figs. 6, 7, 9, SM7).

382 Body-wave tomography images a large-volume low-velocity zone with top at $\sim 8 \mathrm{~km}$ depth 383 that is much broader than the caldera. Seismicity broadens with depth to a ca. $18 \mathrm{~km}$-wide zone 384 around the margins of a low P- and S-velocity zone [Tepp et al., 2014] (Fig. 9). This large 385 volume low velocity zone is interpreted as a crystal-mush region that supplies the geochemically 386 monotonous lavas [Reynolds et al., 1995b]. 
The layered magma storage system we image in seismicity and seismic tomography models of the SIGNET array is consistent with elastic deformation models of geodetic data from other ocean island volcanoes. Bagnardi and Amelung [2012] and Chadwick et al. [2011] determine that a deep (ca. $5 \mathrm{~km} \mathrm{bsl)}$ ) as well as a shallow reservoir are required to explain InSAR data from 391 Fernandina, and $\mathrm{Xu}$ et al. [2016] find a similar pattern for the 2015 eruption at Wolf volcano. 392 Seismicity, geodesy, and petrological studies on other basaltic shield complexes in Hawai’i [e.g., 393 Lin et al., 2014], Iceland [Sigmundsson et al., 2010; Keiding and Sigmarsson, 2012], and Afar 394 [Field et al., 2012] show layered magmatic systems, suggesting that connected sill complexes are common features of basaltic volcano systems. Note that these seismic results, which indicate a 396 large number of earthquakes located between 2 and $6 \mathrm{~km}$, precludes a crust-wide zone of mush 397 [proposed by Geist et al., 2014].

\subsection{Caldera Fault Systems}

SIGNET data indicate brittle deformation along both caldera-bounding ring faults and the intra-caldera trapdoor fault system. The two fault systems are separated by less than $1 \mathrm{~km}$ 402 along the western and southern side of the caldera, a distance within the range of earthquake 403 location errors. Although larger earthquakes were detected on other volcanoes and on the 404 platform between Sierra Negra and Fernandina volcanoes, only small magnitude $\left(\mathrm{M}_{\mathrm{L}}<1.2\right)$ 405 earthquakes occurred on Sierra Negra volcano during the time period of the experiment, which 406 was a period of rapid inflation (Fig. 9). The majority of microseisms occurred beneath the 407 caldera rim and the sinuous ridge at depths 0-4 $\mathrm{km}$ bsl (Figs., 6, 7, 9). The two migrating 408 swarms of earthquakes in March 2010 and March 2011 may have occurred during fluid 409 migration or degassing episodes. The concentration of brittle deformation near the edges of the 410 caldera, as well as the kinematics of faulting are consistent with numerical simulations of 411 caldera deformation [Jonsson, et al., 2009; Gregg et al., 2012]. The trapdoor fault at the 
412 sinuous ridge enables the ca $2 \mathrm{~km}$-thick caldera lid to rise during high pressure periods, and to

413 deflate extremely rapidly after magma withdrawal [e.g., Amelung et al., 200o], such as the $5 \mathrm{~m}$

414 of subsidence that occurred over a few hours during the 2005 eruption [Geist et al., 2008]. The

415 steep reverse fault focal mechanisms we determine indicate compression in the brittle layer

416 above the shallow melt-rich sill during the inter-eruption period, as predicted by numerical

417 models of stress changes during magma chamber inflation [Chadwick et al., 1991; Jonsson,

418 2009; Gregg et al., 2012; Corbi et al. 2015]. Compression above the inflating magma chamber is

419 more pronounced in models that assume a visco-elastic rheology [Gregg et al., 2012] that may

420 be more appropriate for Sierra Negra volcano, given the very small amount of strain

421 accommodated by microseisms. During periods of inflation, the sinuous ridge may localize

422 compressive strain across the caldera.

423

424 6.4 June 2010 Earthquake Swarm

425 Precise locations of well-correlated waveforms from the June 4-9, 2010 earthquake

426 swarm show an initial upward migration, followed by a more spatially dispersed swarm on the

427 southeastern flank of Sierra Negra volcano (Figs. 6, 7, 9). The earthquake sequence started with

$428 \quad \mathrm{a} \mathrm{M}_{\mathrm{L}} 1.5$ earthquake at 13:34 on 4 June, 2010, and activity intensified on June 7 as activity

429 migrated to the SW (Fig. SM8). Earthquake magnitudes range from 1.4 -0.9 over the following

4306 days, unlike a fault rupture and aftershock sequences. They converge to a segmented structure

431 rising from $11 \mathrm{~km}$ to about $4 \mathrm{~km}$ below sea-level. The initial rupture depth occurred at $11 \mathrm{~km}$,

432 too deep for hydrothermal fluid migration. Taken together, the time-space relations suggest a

433 dike or sill intrusion into the southern flank of Sierra Negra volcano (Fig. SM8). The intrusion

434 lies along the edge of the deeper low-velocity zone imaged in tomographic models [Tepp et al.,

435 2013]. The associated reverse faulting focal mechanisms are consistent with compression at the 
margins of a sill intrusion where stress concentrates [e.g., Maccaferri et al., 2011; Magee et al., 437 2016], but they are not diagnostic.

438 Although no deformation signal was detected in InSAR data, and the GPS array does not 439 enclose the intrusion site, independent analyses support the interpretation of a lower crustal sill 440 or dike intrusion. Kelly et al. [2013] use back projection methods to map a time variation in 441 seismic velocity on the southeastern flank of Sierra Negra. Shear-wave splitting measurements 442 of crustal anisotropy showed a $90^{\circ}$ rotation in the fast direction during and after the June 2010 443 swarm [Anzieta et al., 2013]. By analogy to temporal changes in anisotropy direction at

444 Ruapehu volcano, the temporal change in crustal anisotropy direction suggests a possible stress

445 field change associated with depressurization of the magma chamber [e.g, Gerst and Savage, 446 2004]. Possible analogies at other Galápagos volcanoes include a subvolcanic lateral sill 447 intrusion at $\sim 5 \mathrm{~km}$ below sealevel on the southern flank of Fernandina volcano in 2007 448 [Bagnardi and Amelung, 2012], and the Urvina bay uplift associated with sill intrusion [Poland, 449 2014]. These observations suggest that ocean island volcanoes regularly grow by intrusion as 450 well as eruption.

452 6. 4 Earthquakes and the Eruption Cycle

453 Given the proximity of the volcanoes in the Western Galápagos, teleseismic events cannot be 454 well correlated with specific volcanoes. Instead, we construct a cumulative frequency diagram 455 in Figure 10 showing teleseismic moment release in an area encompassing Isabela and 456 Fernandina Islands to evaluate the relationship between teleseismic activity and eruptions and 457 large volume intrusions. We superpose episodes of eruption of confirmed dike/sill intrusion on 458 the 7 Isabela and Fernandina volcanoes during the same time period (Fig. 10). For those 459 eruptions and intrusions with geodetic constraints (since 1995), most of the earthquake activity 460 is along ring fault systems bounding the calderas, dike intrusions and fissure eruptions, and the 
trapdoor fault at Sierra Negra [e.g., Chadwick et al., 2006; Yun et al., 2007; Geist et al., 2008;

462 Bagnardi and Amelung, 2012; Shuler et al., 2013] (Fig. 3). One of the main outcomes of this 463 study is documenting that the inter-eruption inflation cycle on Sierra Negra occurs largely 464 aseismically.

Our comparison, and historic data, indicate that $\mathrm{M}>4$ earthquakes are largely restricted to eruptions and known large volume intrusion events beneath the main caldera and flanks.

467 Considering that only small magnitude earthquakes occurred during the period of rapid 468 inflation of the Sierra Negra caldera in 2009-2011 and the $b$-value indicates efficient stress 469 release, our results indicate that almost all of the inter-eruption inflation was accommodated by 470 aseismic deformation. The longer-term record indicates that potentially damaging earthquakes 471 (M4-M6) occur during eruption, large volume intrusions, and trapdoor faulting events (Fig. 10).

\section{CONCLUSIONS}

476 earthquakes on Sierra Negra volcano $\left(M_{L}<1.5\right)$ and the surrounding areas during a period of 477 magma inflation as determined from InSAR and GPS data. Larger magnitude earthquakes 478 occurred in swarms at Alcedo $\left(M_{L} \leq 3.5\right)$ and Fernandina $\left(M_{L} \leq 3.2\right)$, and at the persistent 479 spatial cluster beneath the shallow submarine platform between Sierra Negra and Fernandina 480 volcanoes. The correlation of the offshore swarm (within location errors) with morphologically 481 young eruptive cones suggests that a pressurized magma body between the two volcanoes.

482 We interpret the temporal and spatial patterns of seismicity, the focal mechanisms, and 483 existing tomographic and geodetic models as evidence for a shallow melt-rich sill with a top at 484 ca. $1 \mathrm{~km}$ bsl below the Sierra Negra caldera, and a base at $2 \mathrm{~km}$ bsl. Focal mechanisms indicate 485 compression in the rocks around the shallow sill, a pattern consistent with models of stresses 486 induced by shallow sill inflation. The melt-rich sill is underlain by a seismogenic crust above the 
487 tomographically-imaged low-velocity zone interpreted as a broad, crystal-mush magma

488 chamber with a top between 6-8 $\mathrm{km}$ depth. Upward migrating swarms of earthquakes occurred

489 on the southeastern flank of Sierra Negra volcano in June 2010, and their spatially segmented

490 pattern suggests an intrusion at depths 5-11 km bsl. Seismic strain was very small during the 2-

491 year period of caldera inflation, indicating that almost all of the inter-eruption inflation (o.78 m)

492 occurred aseismically. The time-space distribution of seismicity and the high b-value suggest

493 potentially damaging earthquakes are unlikely during the interseismic cycle, whereas historic

494 data demonstrate increased hazard during large volume intrusions, eruptions, and trapdoor

495 faulting events.

496

497 ACKNOWLEDGEMENTS

498 LD thanks SCEC for providing the opportunity to develop a $3 \mathrm{D}$ visualization of the data set. Bill

499 Chadwick and an anonymous reviewer provided many insightful comments that greatly

500 improved the paper. We are very grateful for the assistance of Marco Bagnardi, Daniel Pacheco,

501 Alex Steele, Sandro Vaca, Luis Manzanillas from Instituto Geofisico, undergraduate students

502 Caitlin Smigelski, Megan O’Connor, and Nate Lindsey, science teacher Lisa Hjelm (Girls Middle

503 School, Mountain View), and Eliana Arias of PASSCAL in the physically challenging data

504 acquisition by foot, pony, and boat. We are grateful to Captain Lenin Cruz and Roberto Pepolas

505 for their continued advice and for ensuring our safety during the land and sea travels. This work

506 was supported by NSF grant EAR 0924239 to C.E, F.A. and D. G., Parque Nacional de

507 Galápagos, and the Charles Darwin Foundation. D.G.'s effort is based upon work while serving

508 at the National Science Foundation.

509 References 
Amelung, F., S. Jónsson, H. Zebker, and P. Segall, 2000. Widespread uplift and trap door faulting on Galápagos volcanoes observed with radar interferometry, Nature, 407(6807), 993-996.

Anzieta, J., 2013. Estudio de anisotropia sismica para la determinacion de los esfuerzos tectonicos en el volcan Sierra Negra, Galápagos, MSc Thesis, Escuela Politecnica Nacional, Quito, Ecuador.

Bagnardi, M., and F. Amelung, 2012. Space-geodetic evidence for multiple magma reservoirs and subvolcanic lateral intrusions at Fernandina Volcano, Galápagos Islands, J. Geophys. Res., 117, B10406, doi:10.1029/2012JBo09465.

Baker, M. S., 2012. Investigating the Dynamics of Basaltic Volcano Magmatic Systems with Space Geodesy. Open Access Dissertations. Paper 917.

Brandsdottir, B. and Einarsson, P., 1979. Seismic activity associated with the September 1977 deflation of the Krafla central volcano in northeastern Iceland. Journal of Volcanology and Geothermal Research, 6(3-4), pp.197-212.

Chadwick, W. W., and K. A. Howard, 1991. The pattern of circumferential and radial eruptive fissures on the volcanoes of Fernandina and Isabela islands, Galápagos, Bull. of Volc., 53(4), 259-275.

Chadwick W.W., D.J. Geist, S. Jonsson, M. Poland, and D.J. Johnson, 2006. A volcano bursting at the seams: inflation, faulting, and eruption at Sierra Negra Volcano, Galápagos, Geology, 34, 1025-1028.

Chadwick, W. W., Jr., S. Jónsson, D. J. Geist, M. Poland, D. J. Johnson, S. Batt, K. S. Harpp, and A. Ruiz, 2011. The May 2005 eruption of Fernandina volcano, Galápagos: The first circumferential dike intrusion observed by GPS and InSAR, Bull. Volcanol., 73(6), 679-697, doi: 10.1007/s00445-010-0433-0.

Chestler, S.R. and Grosfils, E.B., 2013. Using numerical modeling to explore the origin of intrusion patterns on Fernandina volcano, Galápagos Islands, Ecuador. Geophysical Research Letters, 40(17), pp.4565-4569.

Coffin, M. F., and O. Eldholm, 1994. Large igneous provinces: crustal structure, dimensions, and external consequences, Reviews of Geophysics, 32(1), 1-36.

Colgan, M.W. and Malmquist, D.L., 1987. The Urvina Bay uplift - a dry trek through a Galápagos coral reef. Oceanus, 3o(2), pp.61-68.

Corbi, F., Rivalta, E., Pinel, V., Maccaferri, F., Bagnardi, M. and Acocella, V., 2015. How caldera collapse shapes the shallow emplacement and transfer of magma in active volcanoes. Earth and Planetary Science Letters, 431, pp.287-293. 
Ekström, G., Nettles, M. and Dziewoński, A.M., 2012. The global CMT project 2004-2010: centroid-moment tensors for 13,017 earthquakes. Physics of the Earth and Planetary Interiors, 200, pp.1-9.

Feighner, M. A., and M. A. Richards, 1994, Lithospheric structure and compensation mechanisms of the Galápagos Archipelago, J. Geophys. Res., 99(B4), 6711-6729, doi:10.1029/93JB03360.

Field, L., Blundy, J., Brooker, R.A., Wright, T. and Yirgu, G., 2012. Magma storage conditions beneath Dabbahu Volcano (Ethiopia) constrained by petrology, seismicity and satellite geodesy. Bulletin of Volcanology, 74(5), pp.981-1004.

Filson, J., Simkin, T. and Leu, L.K., 1973. Seismicity of a caldera collapse: Galápagos Islands 1968. Journal of Geophysical Research, 78(35), pp.8591-8622.

Fontaine, F.R., Hooft, E.E., Burkett, P.G., Toomey, D.R., Solomon, S.C. and Silver, P.G., 2005. Shear-wave splitting beneath the Galápagos archipelago. Geophysical Research Letters, 32(21).

Fox, C. G., H. Matsumoto, and T.-K. A. Lau, 2001. Monitoring Pacific Ocean seismicity from an autonomous hydrophone array, J. Geophys. Res., 106(B3), 4183-4206, doi:10.1029/2000JB900404.

Geist, D. J., D. J. Fornari, M. D. Kurz, K. S. Harpp, S. A. Soule, M. R. Perfit, and A. M. Koleszar, 2006. Submarine Fernandina: Magmatism at the leading edge of the Galápagos hot spot, Geochem. Geophys. Geosyst., 7, Q12007, doi:10.1029/2006GCo01290.

Geist, D. J., K. S. Harpp, T. R. Naumann, M. Poland, W.W. Chadwick, M. Hall, and E. Rader, 2008. The 2005 eruption of Sierra Negra volcano, Galápagos, Ecuador, Bull. of Volc., 70(6), 655-673, doi:10.1007/s00445-007-0160-3.

Geist, D., G. Bergantz, and W. W. Chadwick, Jr., 2014. Galápagos Magma Chambers, in The Galápagos: A Natural Laboratory for the Earth Sciences, edited by K. S. Harpp, et al., pp. 5570, American Geophysical Union, Washington DC.

Gerst, A. and Savage, M.K., 2004. Seismic anisotropy beneath Ruapehu volcano: a possible eruption forecasting tool. Science, 306(5701), pp.1543-1547.

Global Volcanism Program, 2008. Report on Cerro Azul (Ecuador). In: Wunderman, R. (ed.), Bulletin of the Global Volcanism Network, 33:5. Smithsonian Institution, http://dx.doi.org/10.5479/si.GVP.BGVN200805-3353060.

Graham, D.W., Christie, D.M., Harpp, K.S. and Lupton, J.E., 1993. Mantle plume helium in submarine basalts from the Galápagos platform. Science, 262(5142), pp.2023-2026. 
Gregg, P.M., De Silva, S.L., Grosfils, E.B. and Parmigiani, J.P., 2012. Catastrophic calderaforming eruptions: Thermomechanics and implications for eruption triggering and maximum caldera dimensions on Earth. Journal of Volcanology and Geothermal Research, 241, 1-12.

Harpp, K. and Geist, D., 2002. Wolf-Darwin lineament and plume-ridge interaction in northern Galápagos. Geochemistry, Geophysics, Geosystems, 3(11), pp.1-19.

Hooft, E.E., Toomey, D.R. and Solomon, S.C., 2003. Anomalously thin transition zone beneath the Galápagos hotspot. Earth and Planetary Science Letters, 216(1), pp.55-64.

Ito, G. T., and J. Lin, 1995. Mantle temperature anomalies along the past and paleoaxes of the Galápagos spreading center as inferred from gravity analyses. J. Geophysical Research, 100, 3733-3745.

Jónsson, S., 2009. Stress interaction between magma accumulation and trapdoor faulting on Sierra Negra volcano, Galápagos, Tectonophysics, 471(1), 36-44.

Jónsson, S., H. Zebker, and F. Amelung, 2005. On trapdoor faulting at Sierra Negra volcano, Galápagos, J. Volc. Geotherm. Res., 144, 59-71.

Keiding, J.K. and Sigmarsson, O., 2012. Geothermobarometry of the 2010 Eyjafjallajökull eruption: New constraints on Icelandic magma plumbing systems. Journal of Geophysical Research: Solid Earth, $117(\mathrm{Bg})$.

Keir, D., Stuart, G.W., Jackson, A. and Ayele, A., 2006. Local earthquake magnitude scale and seismicity rate for the Ethiopian rift. Bulletin of the Seismological Society of America, 96(6), pp.2221-2230.

Kelly, C.L., Lawrence, J.F. and Ebinger, C.J., 2013. Imaging spatial and temporal seismic source variations at Sierra Negra Volcano, Galápagos Islands using back-projection methods, $A G U$ Fall Meeting Abstracts , 1, 2860.

Kissling, E., W. L. Ellsworth, D. Eberhart-Phillips, and U. Kradolfer, 1994. Initial reference models in local earthquake tomography, J. Geophys. Res., 99(B10), 19635-19646, doi: $10.1029 / 93 \mathrm{JB} 03138$.

Kurz, M.D. and Geist, D., 1999. Dynamics of the Galapagos hotspot from helium isotope geochemistry. Geochimica et Cosmochimica Acta, 63(23), pp.4139-4156.

Lin, G., Shearer, P.M., Matoza, R.S., Okubo, P.G. and Amelung, F., 2014. Three-dimensional 607 seismic velocity structure of Mauna Loa and Kilauea volcanoes in Hawaii from local seismic 608 tomography. Journal of Geophysical Research: Solid Earth, 119(5), pp.4377-4392. 
Lyons, J., D. Geist, K. Harpp, B. Diefenbach, P. Olin, and J. Vervoort (2007), Crustal growth by magmatic overplating in the Galápagos, Geology, 35, 511-514.

Maccaferri, F., Bonafede, M. and Rivalta, E., 2011. A quantitative study of the mechanisms governing dike propagation, dike arrest and sill formation. Journal of Volcanology and Geothermal Research, 208(1), pp.39-50.

Magee, C., J. D. Muirhead, A. Karvelas, S. Holford, C. A.L. Jackson, I. Bastow, N. Schofield, C. T.

Murru, M., Montuori, C., Wyss, M. and Privitera, E., 1999. The locations of magma chambers at Mt. Etna, Italy, mapped by b-values. Geophysical research letters, 26(16), pp.2553-2556.

Pinel, V. and Jaupart, C., 2003. Magma chamber behavior beneath a volcanic edifice. Journal of Geophysical Research: Solid Earth, 108(B2), 10.1029/2002JB001751

Poland, M., 2014. Contrasting volcanism in Hawai'i and the Galápagos, in K. S. Harpp, E. Mittelstaedt, N. d'Ozouville, D. W. Graham, eds., The Galápagos: A Natural Laboratory for the Earth Sciences, Geophysical Monograph 204.

Reyes, C.G. and West, M.E., 2011. The waveform suite: A robust platform for manipulating waveforms in MATLAB. Seismological Research Letters, 82(1), pp.104-110. Island, Galápagos archipelago, J. Geophys. Res., 100(B12), 24537-24553, doi:10.1029/95JBo2809.

Reynolds, R. W., D. Geist, and M. D. Kurz, 1995b. Physical volcanology and structural development of Sierra Negra volcano, Isabela island, Galápagos archipelago, Geological Soc. of Am. Bull., 107(12), 1398-1410.

Rodd, R.L., Lees, J.M. and Tepp, G., 2016. Three-dimensional attenuation model of Sierra Negra Volcano, Galápagos archipelago. Geophysical Research Letters, 43(12), pp.6259-6266. 
Rychert, C.A., Harmon, N. and Ebinger, C., 2014. Receiver function imaging of lithospheric structure and the onset of melting beneath the Galápagos Archipelago. Earth and Planetary Science Letters, 388, pp.156-165.

Shuler, A., Nettles, M. and Ekström, G., 2013. Global observation of vertical-CLVD earthquakes at active volcanoes. Journal of Geophysical Research: Solid Earth, 118(1), pp.138-164.

Sigmundsson, F., Hreinsdóttir, S., Hooper, A., Árnadóttir, T., Pedersen, R., Roberts, M.J., Óskarsson, N., Auriac, A., Decriem, J., Einarsson, P. and Geirsson, H., 2010. Intrusion triggering of the 2010 Eyjafjallajokull explosive eruption. Nature, 468(7322), pp.426-430.

Snoke, J.A., 2003. 85.12 FOCMEC: FOCal MEChanism determinations. International Geophysics, 81, pp.1629-1630.

Soule, S. A., V. D. Wanless, D. Fornari, M. Jones, D. Schwartz, M. A. Richards, 2016. Morphology of Galapagos platform seamounts: A history of emergence and submergence, Eos, Trans. Amer. Geophys. Union.

Tepp, G., C. Ebinger, M. Ruiz, and M. Belachew, 2014. Imaging rapidly deforming ocean island volcanoes in the western Galápagos archipelago, Ecuador, J. Geophys. Res., 119, 442-463.

Toomey, D.R., Hooft Toomey, E.E., Hooft Toomey, E.E. and Detrick, R.S., 2001. December. Crustal thickness variations and internal structure of the Galápagos Archipelago. In $A G U$ Fall Meeting Abstracts, 1, 0939.

Villagómez, D.R., Toomey, D.R., Hooft, E.E. and Solomon, S.C., 2007. Upper mantle structure beneath the Galápagos Archipelago from surface wave tomography. Journal of Geophysical Research: Solid Earth, 112(B7).

Villagómez, D.R., Toomey, D.R., Hooft, E.E. and Solomon, S.C., 2011. Crustal structure beneath the Galápagos Archipelago from ambient noise tomography and its implications for plume-lithosphere interactions. Journal of Geophysical Research: Solid Earth, 116(B4).

Villagómez, D.R., Toomey, D.R., Geist, D.J., Hooft, E.E. and Solomon, S.C., 2014. Mantle flow and multistage melting beneath the Galápagos hotspot revealed by seismic imaging. Nature Geoscience, 7(2), pp.151-156.

Waldhauser, F. and W. Ellsworth. 2000. A double-difference earthquake location algorithm; method and application to the northern Hayward Fault, California. California Bulletin of the Seismological Society of America, 90(6):1353-1368. 
670 Xu, W., Jónsson, S., Ruch, J. and Aoki, Y., 2016. The 2015 Wolf volcano (Galápagos) eruption 671 studied using Sentinel-1 and ALOS-2 data. Geophysical Research Letters, 43(18), pp.95736729580.

673 Yun, S., P. Segall, and H. Zebker, 2006. Constraints on magma chamber geometry at Sierra 674 Negra Volcano, Galápagos Islands, based on InSAR observations, J. Volc. Geotherm. Res., $675150,232-243$.

676 Yun, S.-H., H. Zebker, P. Segall, A. Hooper, and M. Poland, 2007. Interferogram formation in 677 the presence of complex and large deformation, Geophys. Res. Lett., 34, L12305, 
doi:10.1029/2007GL029745. 


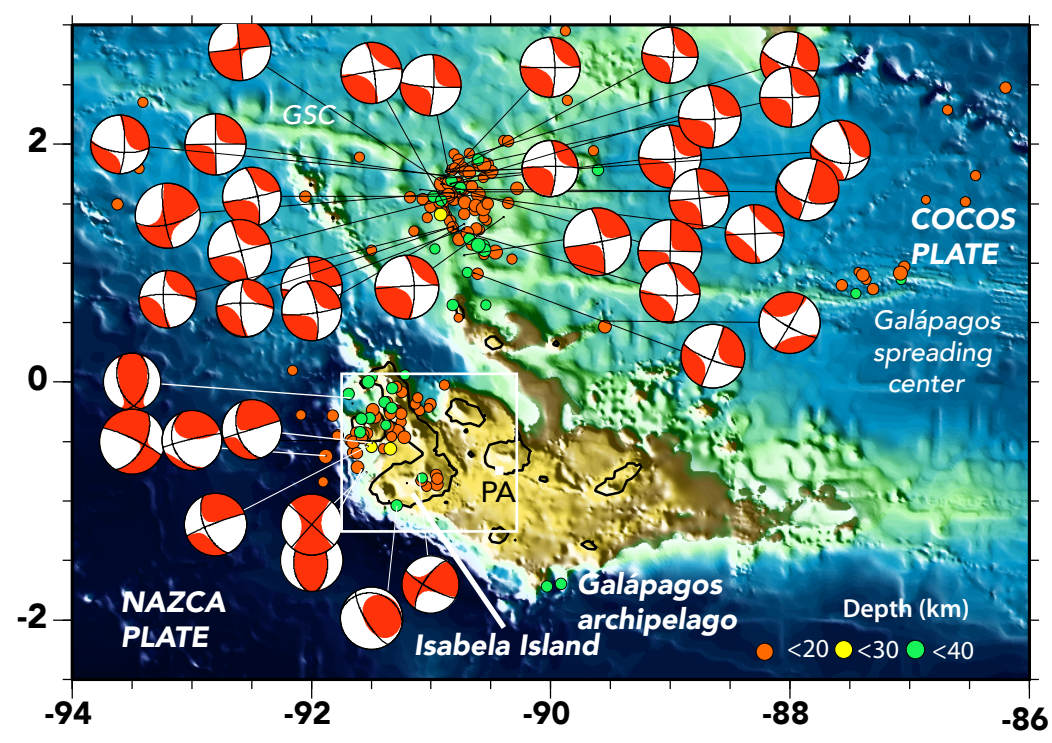

Figure 1. Seismicity of Isabela Island with respect to the Galápagos archipelago, and the Galápagos spreading center between the Nazca and Cocos oceanic plates. PA is Puerto Ayora, the location of Global Seismic Network station PAYG. Global Centroid Moment Tensors spanning 1976 to June 2016 shown in red and scaled to magnitude [Ekstrom et al., 2012]. The magnitude range is 4.5 to 5.9. Circles indicate earthquakes from the NEIC catalogue, with depths as indicated. 


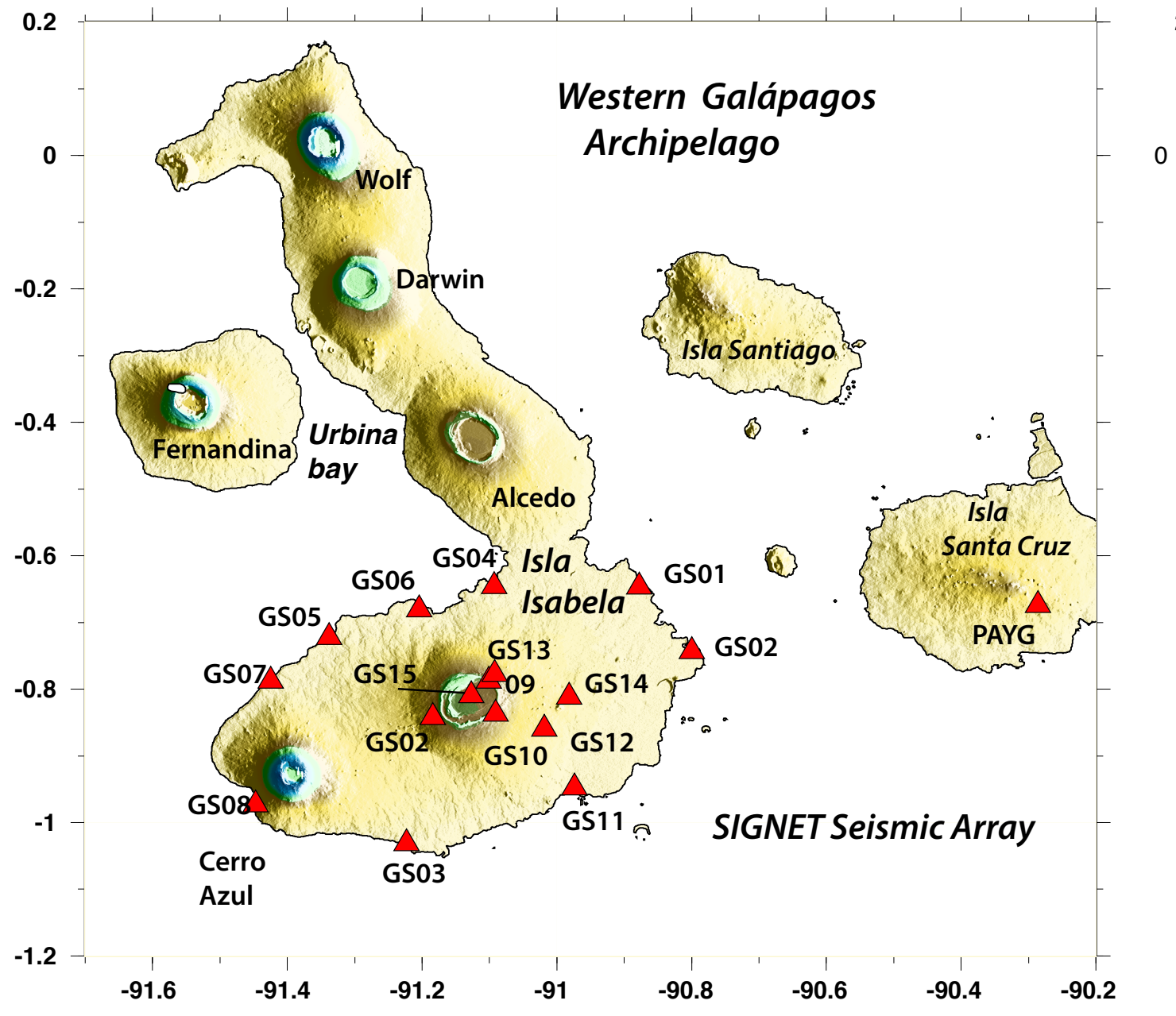

Figure 2. Active volcanoes of the western Galápagos Archipelago, and the SIGNET broadband seismic array deployed on southern Isabela Island between July 2009 and June 2011, and GSN station PAYG on Isla Santa Cruz. See box in Fig. 1 for regional location. 


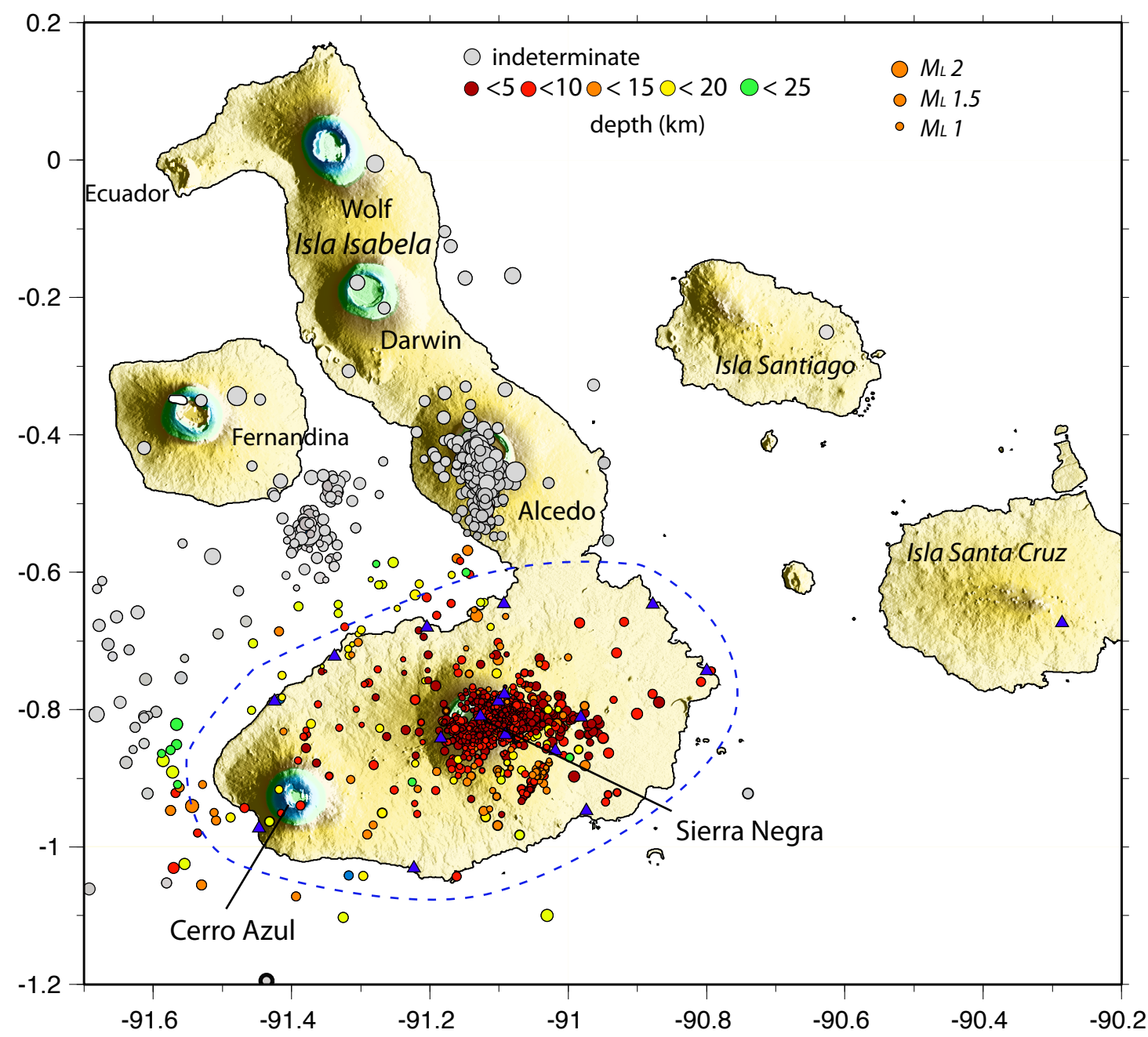

Figure 3. Absolute earthquake locations with size scaled by magnitude, and color scaled by depth. The dashed line encloses the region with well-determined depths: earthquakes outside the dashed lines have large depth errors, or indeterminate depths (gray). Note the cluster of earthquakes on the shallow platform between Sierra Negra, Fernandina, and Alcedo volcanoes, and the persistent swarm in the shallow shelf between Sierra Negra and Fernandina volcanoes. 


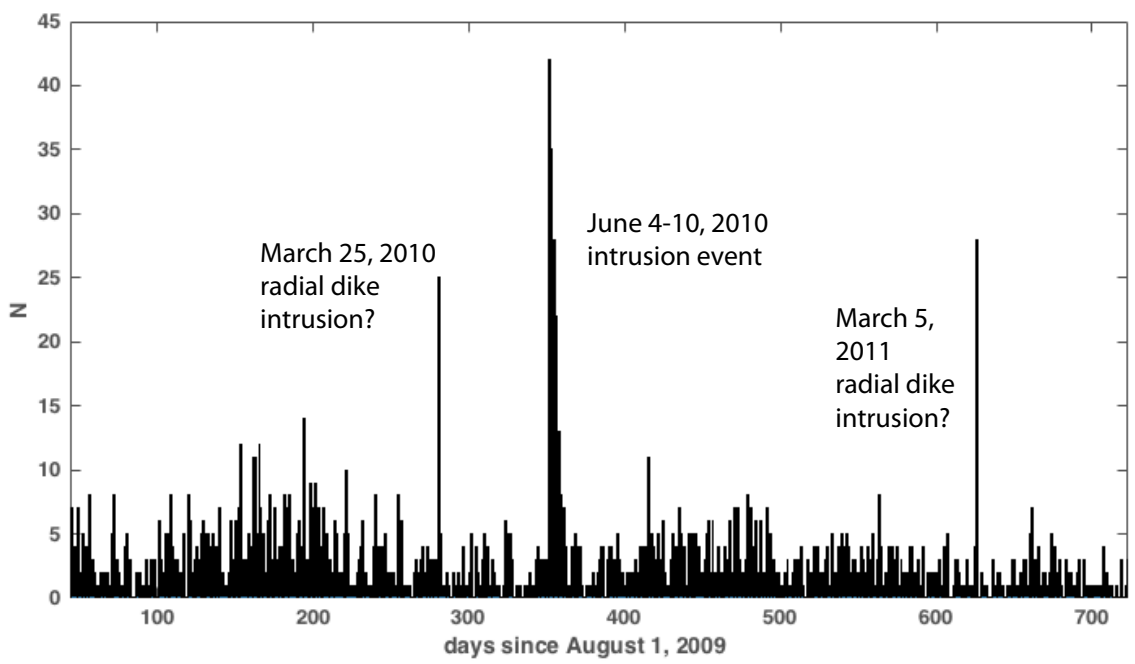

Figure 4. Histogram of earthquake occurrence within the Isabela seismic array in days since August 1, 2009 (see Fig. SM7 for time histogram of Alcedo earthquakes). The two migrating swarms along the ring fault system (March 25, 2010, March 5 2011), and the June 4-10, 2010 intrusion event on the SE flank of Sierra Negra dominate the background level of 5-10 earthquakes per day. Although some instruments had gaps in coverage, the array geometry was maintained throughout the experiment.

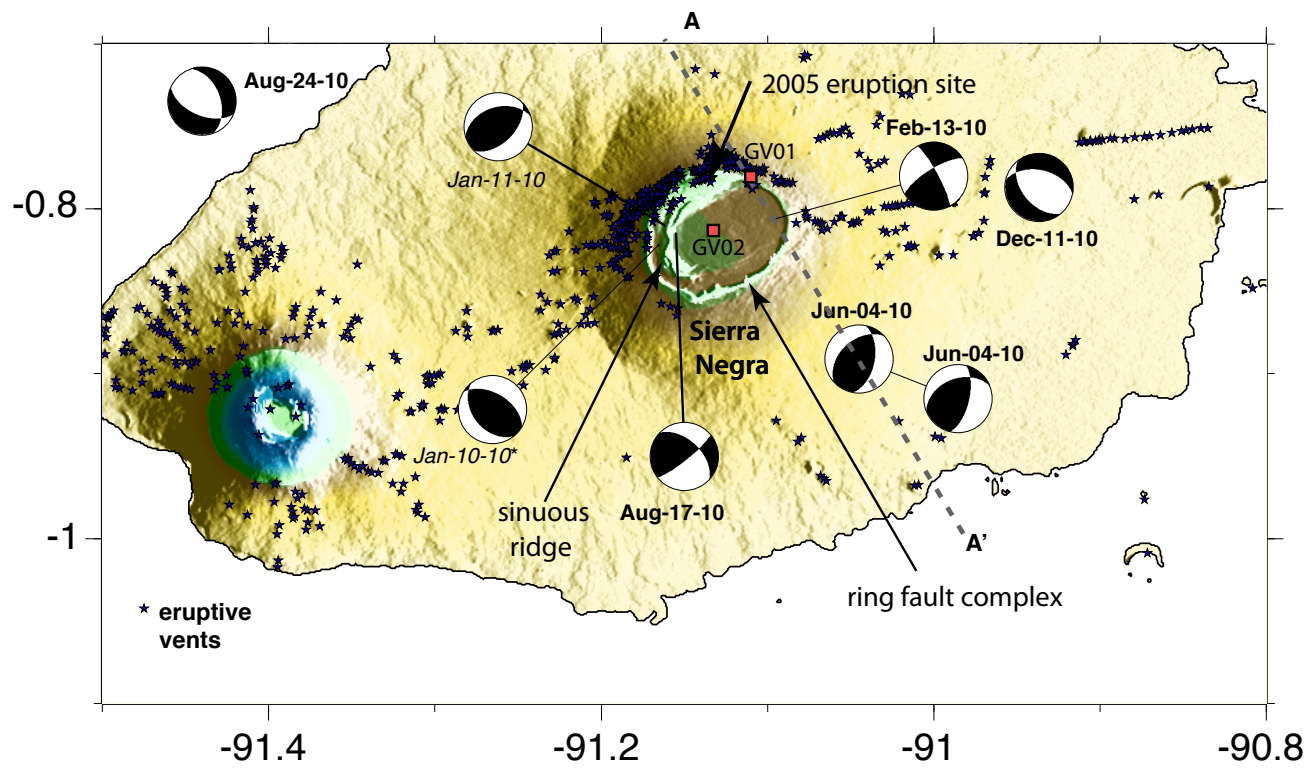

Figure 5. Eruptive vents and cones (stars) and focal mechanisms of earthquakes detected by the SIGNET array overlain on SRTM-30 digital elevation model of Sierra Negra and Cerro Azul volcanoes forming southern Isla Isabela in the western Galápagos Archipelago. Locations of eruptive vents, cones, and fissures mapped from Google Earth imagery, calibrated by maps of Reynolds et al. (1995b). Cloud cover obscured a few areas on Cerro Azul volcano. A-A' is line of cross-section shown in Figure 9. 


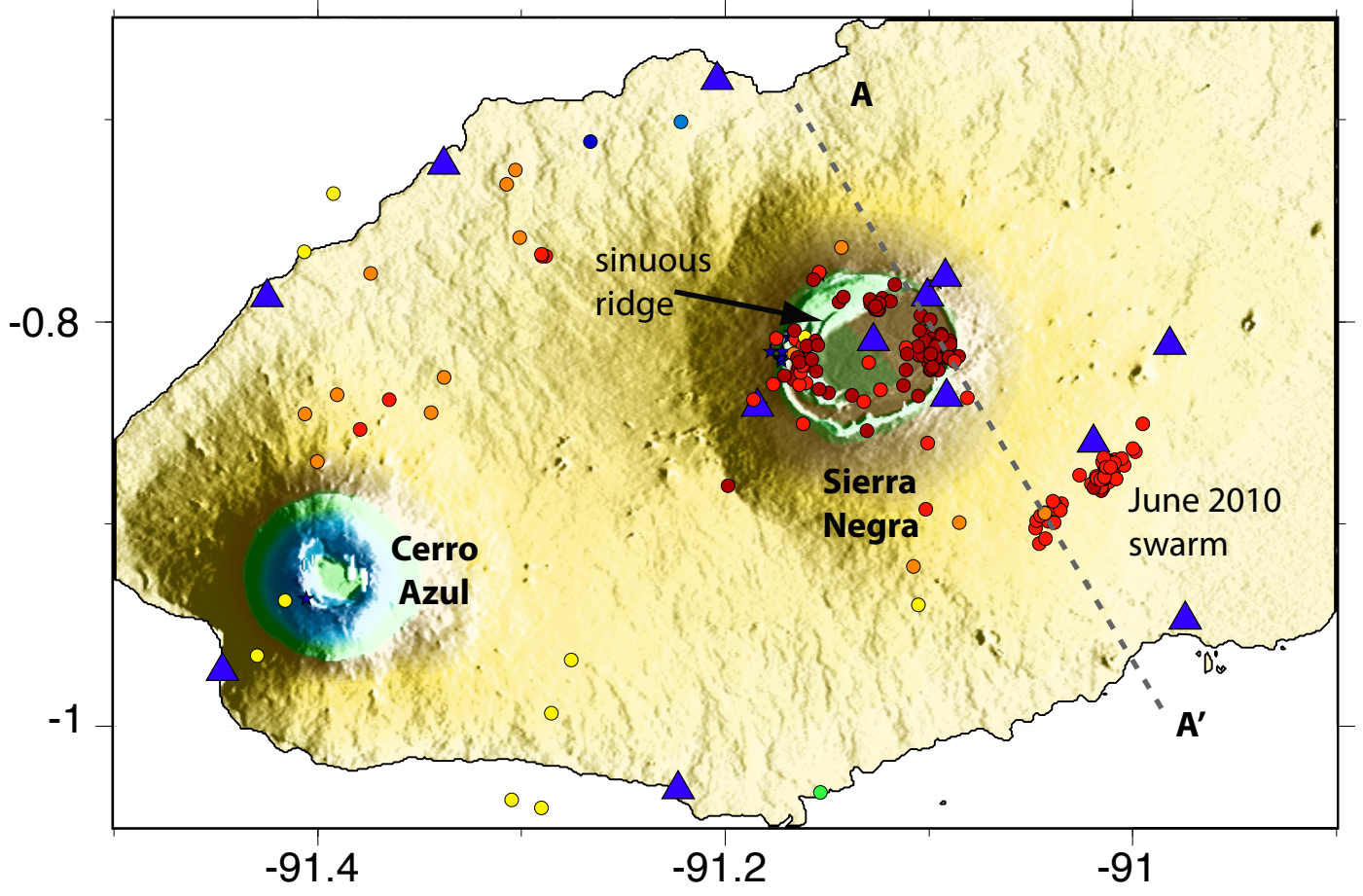

Figure 6. Double-difference earthquake locations of earthquakes from the caldera region of Sierra Negra volcano, and the June 2010 earthquake swarm. A-A' is the line of cross-section shown in Figure 9. Blue triangles are seismometer locations. 


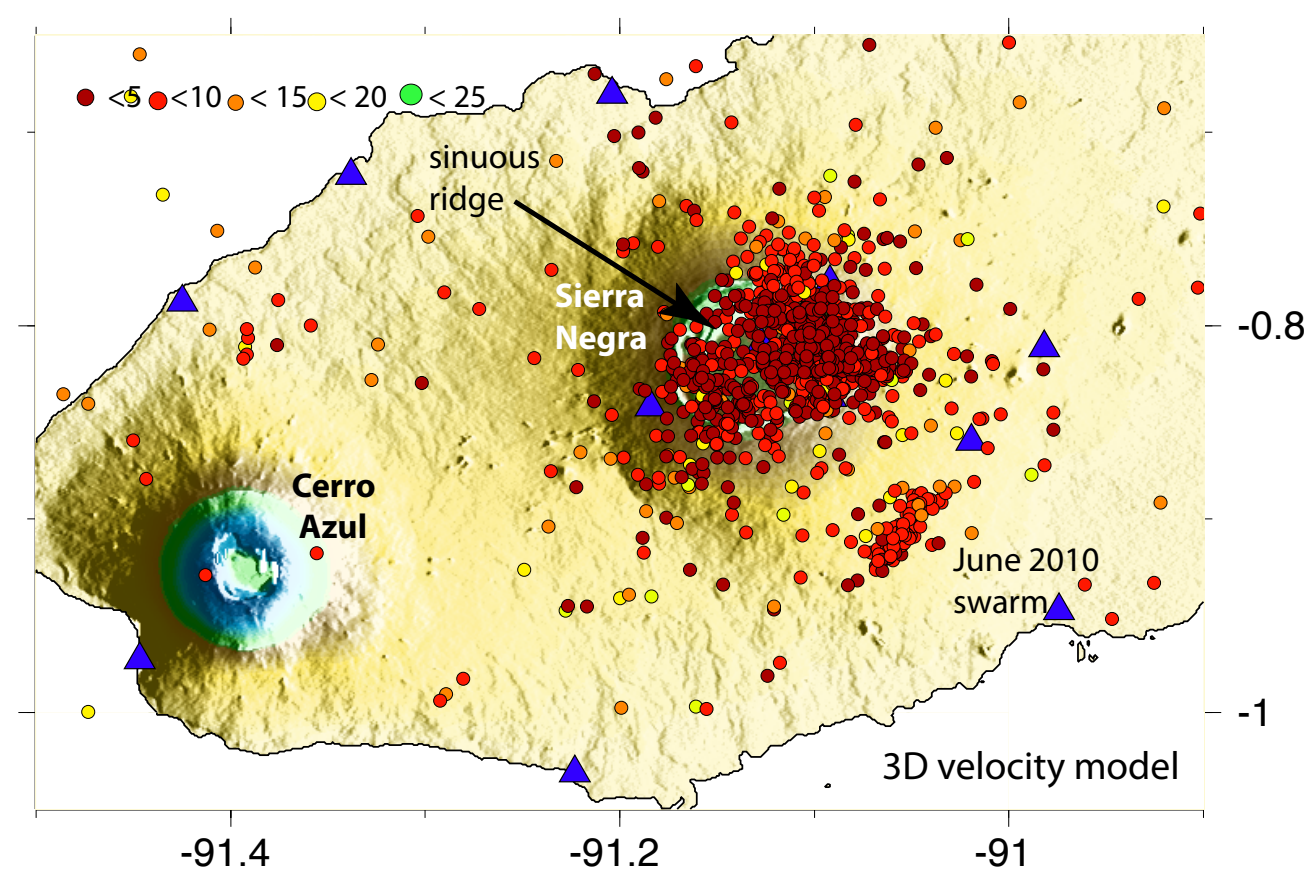

Figure 7. Sub-set of earthquakes relocated using the 3D velocity model of Tepp et al. [2014]. Note the large number of earthquakes in the uppermost $2 \mathrm{~km}$, most of which were rejected in the double difference algorithm.

N

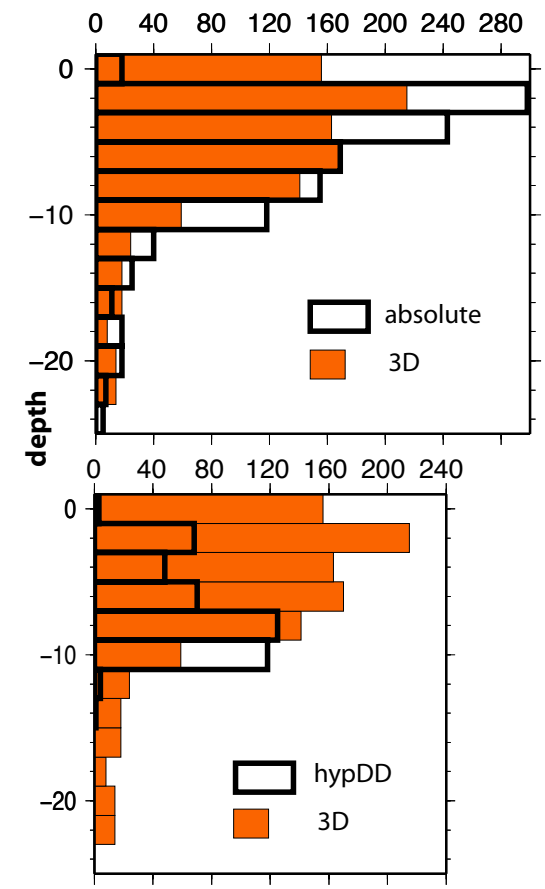


Figure 8. Depth histograms of earthquake locations determined using the 3D velocity model of Tepp et al. [2014], absolute locations, and the caldera region and June 2010 earthquake swarms relocated using hypoDD. For both top and bottom, note the much larger number of earthquakes within the depth range 1 to $1 \mathrm{~km}$ in the 3D velocity, as compared to the hypoinverse and hypoDD results. Many of these earthquakes were excluded from both methods owing to the large errors or location above mean ground level in both the hypoinverse and hypoDD methods. a) Comparison of the locations determined by the 3D velocity model and absolute locations; b) Comparison of the 3D inversion and the double-difference inversion results. The double-difference results include all of the $>200$ June 2010 earthquakes, whereas only a subset were included in the 3D inversion.

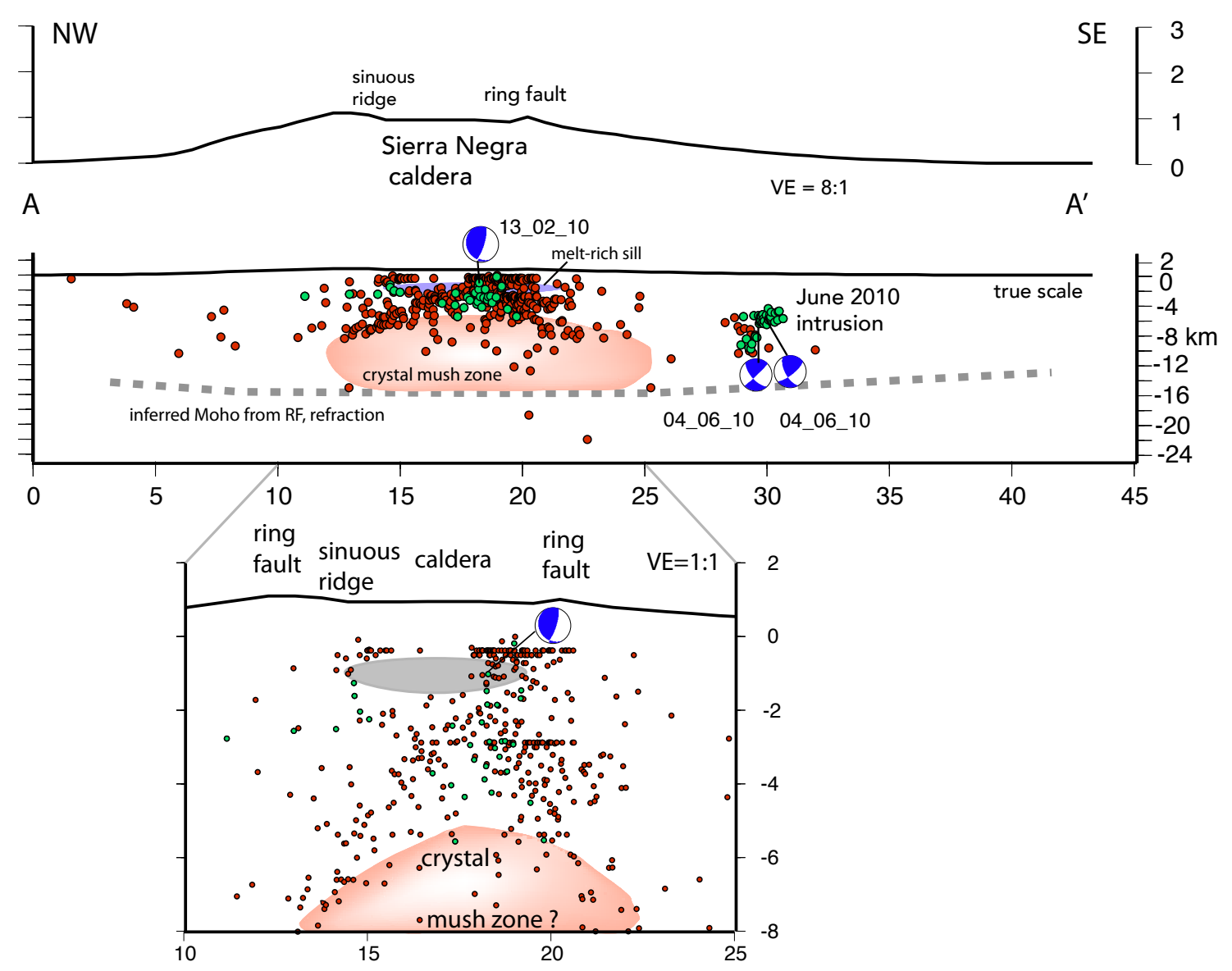

Figure 9. Topography and earthquake locations relocated using double difference (green) and 3D velocity model of Tepp et al. (2014) along profile A-A' shown in Figures 6, 7. Earthquakes projected from $\pm 1 \mathrm{~km}$ of line A-A', which crosses the sinuous ridge, the cluster of earthquakes beneath the NE side of the broad Sierra Negra caldera, and the June 2010 intrusion, near the site of the first earthquakes in the intense earthquake swarm. The top of the melt-rich sill is inferred from inverse models of ground deformation (Yun et al., 2007) and attenuation tomography (Rodd et al., 2016), and the crystal-mush rich magma chamber is from Tepp et al. (2013). Crustal thickness inferred from receiver function (Rychert et al., 2014) and refraction studies (Toomey, 2001). 


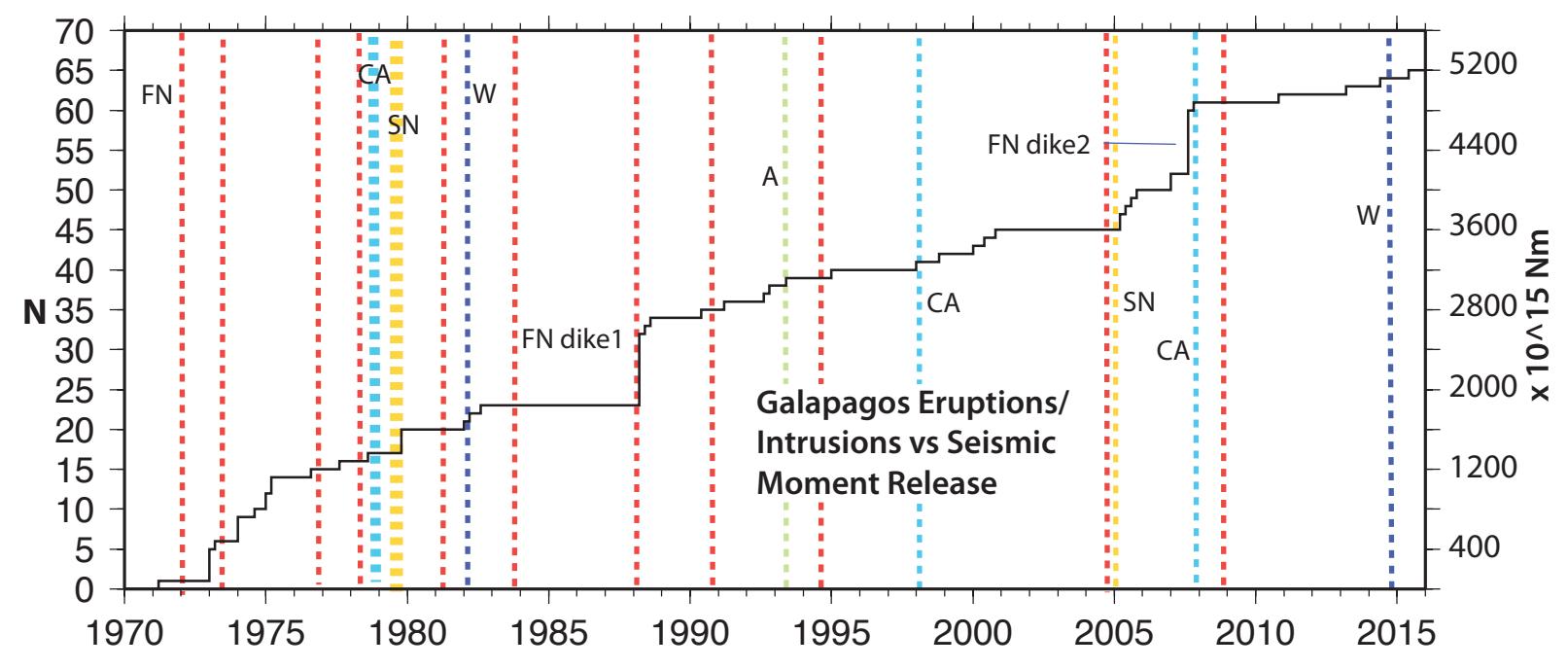

Figure 10. Cumulative histogram of seismic release between 1973 and May, 2016. Vertical bars denote the time period of surface eruptions and confirmed intrusion events at $\mathrm{CA}=\mathrm{Cerro}$ Azul (cyan); $\mathrm{SN}=$ Sierra Negra (yellow); $\mathrm{A}=$ Alcedo (green); FN= Fernandina (red); W = Wolf (blue) volcanoes. Note the large jumps in seismic energy release corresponding to eruptions and independently confirmed magma intrusions.

Table 1. Earthquake focal mechanism results. Depths below sealeval are from 3D velocity model. Solutions vary by $\leq 20^{\circ}$ in strike, dip and rake; * indicates results with nodal plane 1 fits to $\pm 25^{\circ}$ for strike, dip, rake.

\begin{tabular}{|l|l|l|l|l|l|l|l|}
\hline Date & Longitude & Latitude & Depth & Strike & Dip & Rake & $\mathrm{M}_{\mathrm{L}}$ \\
\hline${ }^{*} \mathrm{O} 1 / 10 / 10,16: 49$ & -91.1653 & -0.8217 & 1.5 & 301 & 51 & 77 & 1.1 \\
\hline${ }^{*} 01 / 11 / 10,06: 10$ & -91.1618 & -0.8100 & 0.3 & 44 & 52 & 71 & 1.0 \\
\hline $02 / 13 / 10,11: 01$ & -91.0973 & -0.8065 & 1.3 & 332 & 80 & 17 & 0.9 \\
\hline $06 / 04 / 10,13: 37$ & -91.0410 & -0.8930 & 5.7 & 13 & 54 & 56 & 1.2 \\
\hline $06 / 04 / 10,16: 23$ & -91.0448 & -0.8910 & 6.1 & 11 & 53 & 65 & 1.5 \\
\hline $08 / 17 / 10,23: 03$ & -91.1550 & -0.8147 & 0.2 & 51 & 80 & 39 & 1.1 \\
\hline $08 / 24 / 10,10: 51$ & -91.4400 & -0.7243 & 13.6 & 340 & 46 & -54 & 1.1 \\
\hline $12 / 11 / 10,14: 06$ & -90.9365 & -0.7868 & 5.0 & 141 & 48 & -63 & 0.9 \\
\hline
\end{tabular}

